\title{
Effect of ingesting caffeine and ephedrine on 10-km run performance
}

\author{
DOUGLAS G. BELL, TOM M. MCLELLAN, and CATHI M. SABISTON \\ Defence and Civil Institute of Environmental Medicine, Toronto, Ontario, CANADA
}

\begin{abstract}
BELL, D. G., T. M. MCLELLAN, and C. M. SABISTON. Effect of ingesting caffeine and ephedrine on 10-km run performance. Med. Sci. Sports Exerc., Vol. 34, No. 2, pp. 344-349, 2002. Background: The ingestion of either caffeine (C) or ephedrine (E) has been shown to improve performance during high-intensity aerobic activity lasting 10-20 min, with an additive effect being found when the combination $(\mathrm{C}+\mathrm{E})$ was ingested. It was the purpose of this study to determine if the addition of $\mathrm{E}$ to $\mathrm{C}$ would improve performance in activity lasting longer than $20 \mathrm{~min}$. Methods: One and one half hours after ingesting a placebo (P), C (4 mg/ $\mathrm{kg}), \mathrm{E}(0.8 \mathrm{mg} / \mathrm{kg})$, or $\mathrm{C}+\mathrm{E}, 12$ subjects performed a 10-km run while wearing a helmet and backpack weighing $11 \mathrm{~kg}$. The trials were performed in a climatic suite at $12-13^{\circ} \mathrm{C}$, on a treadmill where the speed was regulated by the subject. $\dot{\mathrm{VO}}_{2}, \dot{\mathrm{V}} \mathrm{CO}_{2}, \dot{\mathrm{V}}_{\mathrm{E}}$, heart rate (HR), and rating of perceived exertion (RPE) were measured during the run at 15 and $30 \mathrm{~min}$, and again when the individual reached $9 \mathrm{~km}$. Blood was sampled at 15 and $30 \mathrm{~min}$ and again at the end of the run and assayed for lactate, glucose, and catecholamines. Results: Run times (mean $\pm \mathrm{SD})$, in minutes, were for $\mathrm{C}(46.0 \pm 2.8)$, $\mathrm{E}(45.5 \pm 2.9), \mathrm{C}+\mathrm{E}(45.7 \pm 3.3)$, and $\mathrm{P}(46.8 \pm 3.2)$. The run times for the $\mathrm{E}$ trials $(\mathrm{E}$ and $\mathrm{C}+\mathrm{E})$ were significantly reduced compared with the non-E trials $(\mathrm{C}$ and $\mathrm{P})$. Pace was increased for the $\mathrm{E}$ trials compared with the non-E trials over the last $5 \mathrm{~km}$ of the run. $\mathrm{VO}_{2}$ was not affected by drug ingestion. HR was elevated for the ephedrine trials $(\mathrm{E}$ and $\mathrm{C}+\mathrm{E})$. RPE remained similar for all trails. Caffeine increased the epinephrine and norepinephrine response associated with exercise and also increased blood lactate, glucose, and glycerol levels. Ephedrine reduced the epinephrine response but increased dopamine and FFA levels. Conclusion: The previously seen additive nature of $\mathrm{E}$ and $\mathrm{C}$ was not evident in this study, with the primary ergogenic effect being attributed to E. Key Words: ERGOGENIC AIDS, CAFFEINE, EPHEDRINE, PHYSICAL PERFORMANCE
\end{abstract}

$\mathrm{R}$ ecent studies have demonstrated that combined caffeine $(\mathrm{C})$ and ephedrine $(\mathrm{E})$ ingestion have increased cycle time to exhaustion at $85 \% \dot{\mathrm{V}}_{2 \max }$ in a controlled laboratory setting (5) and decreased the time required to run a $3.2-\mathrm{km}$ distance in a less controlled setting that simulated the military demands of carrying a rifle and ammunition and wearing a helmet (3). Although military personnel may be involved in sustained high-intensity exercise of 10- to 20-min duration, physical demands requiring lower intensity and longer duration efforts are more common.

It is known that $\mathrm{C}$ ingestion alone has improved performance during prolonged work $(18,29,30)$, with peripheral and central mechanisms postulated to support the ergogenic effect $(12,28)$. Pseudoephedrine, an ephedrine-like substance, has been used during prolonged $40-\mathrm{km}$ cycling trials but was found not to be ergogenic (17). However, the dose of pseudoephedrine used was equivalent to about half the dose of $\mathrm{E}$ used in the previous study (5), where E showed an ergogenic effect. The ergogenic effect of $\mathrm{C}+\mathrm{E}$ is known to be additive during exercise tests lasting from 10-20 $\min (5)$, and the effect appears to be mediated centrally through a lowered perception of effort at a given oxygen demand (5). Whether $\mathrm{C}+\mathrm{E}$ ingestion would offer similar or greater improvement to the ingestion of $\mathrm{C}$ alone in longer activity is

0195-9131/02/3402-0344/\$3.00/0

MEDICINE \& SCIENCE IN SPORTS \& EXERCISE ${ }_{\circledast}$

Copyright $\odot 2002$ by the American College of Sports Medicine

Submitted for publication October 2001.

Accepted for publication April 2001. not known. If positive, this could make the decision to use such an ergogenic aid during military operations easier, especially in situations where the success of a mission could be affected.

Thus, the purpose of this study was to determine if $\mathrm{C}+$ $\mathrm{E}$ could enhance performance in activities that last longer than 10-20 min and whether the improvement would be greater than the ergogenic effects of either $\mathrm{C}$ or $\mathrm{E}$ alone. It was hypothesized that the ergogenic effect on $10-\mathrm{km}$ run time would be greater following the combined ingestion of $\mathrm{C}+\mathrm{E}$ than following the ingestion of either $\mathrm{C}$ or $\mathrm{E}$ alone.

\section{METHODS}

Subjects. Twelve subjects, 10 men and 2 women, with a mean \pm SD age of $33 \pm 8 \mathrm{yr}$, weight of $75 \pm 11 \mathrm{~kg}$, height of $178 \pm 8 \mathrm{~cm}$, and peak aerobic power $\left(\mathrm{V}_{2 \text { peak }}\right)$ of 57.5 $\pm 3.4 \mathrm{~mL} \cdot \mathrm{kg}^{-1} \cdot \mathrm{min}^{-1}$ took part in the study. The total mass used in the expression of $\mathrm{VO}_{2 \text { peak }}$ included an additional 11 $\mathrm{kg}$ of equipment. All subjects were recreational runners and were comfortable running $10 \mathrm{~km}$. Six were regular coffee drinkers, i.e., consuming greater than the equivalent of 1 cup $\cdot \mathrm{d}^{-1}$. Six were irregular or noncaffeine users, i.e., averaging less than the equivalent of 3 cups $\cdot \mathrm{wk}^{-1}$. A medical screening and written informed consent was obtained from all subjects before beginning data collection. The protocol was approved by the institute's ethics review board.

Procedures. Subjects reported to the laboratory on eight different occasions. During the initial visit, subjects were medically screened and had their $\mathrm{V}_{2 \text { peak }}$ determined 
on a motor driven treadmill. This evaluation began at a treadmill speed of $5.5 \mathrm{mph}$ and increased $1 \mathrm{mph}$ every $3 \mathrm{~min}$ until a speed of $7.5 \mathrm{mph}$ was obtained. Thereafter, the grade of the treadmill was increased $1 \%$ per minute until the subject was exhausted. During this test, subjects wore a helmet and a backpack that weighed approximately $11 \mathrm{~kg}$. This was the equipment that was worn during the trials.

Visits 2 and 3 were familiarization trials to the performance test, which was a timed $10-\mathrm{km}$ run. Subjects reported to the laboratory after an overnight 8 - to 12 -h fast. They also had refrained from drinking alcohol for $24 \mathrm{~h}$ and $\mathrm{C}$ before testing. The subject then changed into their running ensemble, which included shorts, T-shirt, socks, and running shoes. A heart rate monitor was strapped around the chest. A catheter (Insyte ${ }^{\circledR}$, Deseret, Sandy, Utah) was then inserted into a forearm vein. After a 15-min rest, which was done in a seated position, a 5-mL blood sample was taken. The subject next put on the helmet and backpack and entered the climatic suite where temperature conditions were maintained at $13^{\circ} \mathrm{C}$. The subject then commenced a warm-up run of approximately $2 \mathrm{~min}$ on the treadmill. Once an appropriate speed was chosen by the subject, a 5 -s count down was given, stopwatches were started, distance covered on the treadmill monitor was reset, and the trial commenced. At this time, the subject was told to finish the $10-\mathrm{km}$ run as quickly as possible. Throughout the trial, the subject controlled the speed of the treadmill, and only the distance covered was displayed. Once during these familiarization trials, an additional 5-mL blood sample was collected that was not used in subsequent analyses. A minimum of $1 \mathrm{wk}$ intervened between the two familiarization sessions.

Sessions 4-8 consisted of three drug and two placebo treatment trials. These trials were identical to the familiarization sessions except, on arriving at the laboratory, the drug or placebo was immediately ingested. Twenty to 30 min later, a light meal consisting of juice and a muffin was eaten. One hour later, a venous catheter was inserted in an antecubital vein and, after a 15-min rest, a blood sample was drawn before the run. The subjects then entered the chamber and commenced the trial. Treatment trials were randomized and double blind.

Drug and placebo administration. The subjects ingested a placebo (P), C (4 mg. $\mathrm{kg}^{-1}$ body weight), E (0.8 $\mathrm{mg} \cdot \mathrm{kg}^{-1}$ body weight), or $\mathrm{C}+\mathrm{E}$ in combination. The $\mathrm{P}$ consisted of the same number of capsules and contained 300 $\mathrm{mg}$ of a dietary fiber (Metamucil $^{\circledR}$, Procter \& Gamble, Toronto, ON). This amount of Metamucil ${ }^{\circledR}$ was similar to the amount of $\mathrm{C}$ ingested in the $\mathrm{C}$ capsules and was 100 times less than the recommended dose of the product for its intended use as a dietary laxative.

Measurements. During the determination of $\dot{\mathrm{VO}}_{2 \text { peak }}$, oxygen consumption $\left(\mathrm{V}_{2}\right)$ was measured every minute using an automated metabolic cart (OCM-2, AMETEK, Paoli, Pittsburgh, PA). The same metabolic cart system was used to measure $\dot{\mathrm{VO}}_{2}$, carbon dioxide production $\left(\dot{\mathrm{VCO}}_{2}\right)$, and expired ventilation $\left(\dot{\mathrm{V}}_{\mathrm{E}}\right)$ during the $10-\mathrm{km}$ run at minutes $13-15$ and $28-30$ and again for 2 min once the $9-\mathrm{km}$ distance was reached. During the determination of $\mathrm{V}_{2 \text { peak }}$, heart rate was monitored throughout the exercise (Vantage XL, Polar Electro, Inc., Port Washington, NY). During the familiarization and treatment trials, the subject's heart rate was recorded every $5 \mathrm{~min}$. The time taken to cover each kilometer was also recorded. A rating of perceived exertion (RPE) (9) was also taken following the gas exchange measurements.

Blood samples were taken just before exercise, during exercise at 15 and $30 \mathrm{~min}$, and immediately after completion of the run. Between samples, the catheter was kept patent by flushing with heparinized saline $\left(10 \mathrm{IU} \cdot \mathrm{mL}^{-1}\right)$. Plasma obtained from aliquots of each blood sample were assayed for free fatty acid (FFA) (NEFA C kit, Wako Chemicals, Richmond, VA), glycerol (8), norepinephrine, epinephrine, and dopamine (32). Another aliquot of each blood sample was immediately deproteinized and subsequently assayed for glucose (GOD-PAP, Boehringer Mannheim, Germany) and lactate (24). Preexercise plasma samples were also assayed for $\mathrm{C}$ and $\mathrm{E}$ by mass spectrometry (GC-MS) electron-impact, selective-ion monitoring (32).

Data analyses. A dependent $t$-test or a two-factor (trial and time) repeated measures ANOVA was used to compare the responses of the dependent measures during the two $\mathrm{P}$ trials. Since no difference was observed between P trials, averaged values were generated to represent the $\mathrm{P}$ condition in subsequent analyses. A $2 \times 2$ factorial repeated measures ANOVA was then used to determine the effects of $\mathrm{C}$ (present or absent) and $\mathrm{E}$ (present or absent) on the run time. For all other dependent measures, a $2 \times 2$ factorial design (C and $\mathrm{E}$ treatments) with the additional repeated factor of time was used to analyze the responses across treatments and time. When a post hoc comparison was required, a means comparison contrast technique was used and the Huynh-Feldt epsilon factors were used to adjust degrees of freedom for multiple comparisons (16). An intraclass correlation coefficient was calculated as a measure of the reliability of the performance of the $10-\mathrm{km}$ run (21). In addition, a 95\% confidence interval for the within-subject variance was determined according to the methods of Loftus and Masson (23). Statistical significance was accepted at the $P<0.05$ level.

\section{RESULTS}

C and E levels. Plasma C levels (mean \pm SD) $1.75 \mathrm{~h}$ after ingestion and just before exercise were not significantly different between the $\mathrm{C}(53.5 \pm 13.1 \mu \mathrm{M})$ and $\mathrm{C}+$ $\mathrm{E}(55.8 \pm 13.6 \mu \mathrm{M})$ trials. Plasma $\mathrm{E}$ levels were also not significantly different just before exercise in the $\mathrm{E}(0.694 \pm$ $0.152 \mu \mathrm{M})$ and $\mathrm{C}+\mathrm{E}(0.636 \pm 0.191 \mu \mathrm{M})$ trials. There was no evidence of ephedrine in the $\mathrm{P}$ trials just before exercise. Trace levels of $\mathrm{C}(5.4 \pm 0.9 \mu \mathrm{M})$ were found in 3 of the 24 $\mathrm{P}$ trials just before exercise.

10-km time. Four 10-km runs were performed without drugs: two familiarization trials (Fam1 and Fam2) and two $\mathrm{P}$ trials (P1 and P2). Run times in minutes for Fam1, Fam2, $\mathrm{P} 1$, and $\mathrm{P} 2$ were $49.4 \pm 2.9,46.5 \pm 2.9,46.9 \pm 3.3$, and $46.7 \pm 3.4$, respectively. Fam1 was significantly slower 


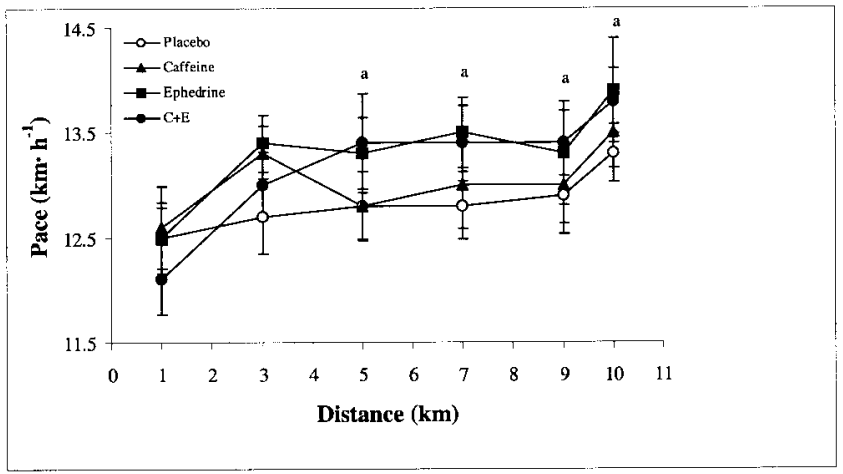

FIGURE 1-Pace during 10-km run. Values are means (SEM). ${ }^{\text {a }}$ trials (ephedrine $[\mathrm{E}]$ and caffeine $[\mathrm{C}]+\mathrm{E}$ ) significantly different from non-E ( $C$ and placebo $[\mathrm{P}])$ trials.

than Fam2, P1, and P2. For the last three trials where performance times were unchanged, the intraclass correlation coefficient was 0.79 and the within-subject $95 \%$ confidence interval was $\pm 0.7 \mathrm{~min}$.

Treatment run times in minutes for $\mathrm{P}, \mathrm{C}, \mathrm{E}$, and $\mathrm{C}+\mathrm{E}$ were $46.8 \pm 3.2,46.0 \pm 2.8,45.5 \pm 2.9$, and $45.7 \pm 3.3$, respectively. The intraclass correlation coefficient for these four trials was 0.86 and the within-subject $95 \%$ confidence interval was $\pm 0.3 \mathrm{~min}$. There was only a main effect of $\mathrm{E}$ where performance times were significantly reduced for the $\mathrm{E}$ trials $(\mathrm{E}$ and $\mathrm{C}+\mathrm{E}, 45.6 \pm 3.1)$ compared with the non-E trials $(\mathrm{C}$ and $\mathrm{P}, 46.4 \pm 3.0)$. There was no difference in this response between $\mathrm{C}$ users $(N=6)$ and nonusers $(N=6)$. Information on pace showed that when $\mathrm{E}$ was ingested ( $\mathrm{E}$ or $\mathrm{C}+\mathrm{E}$ ), the pace was significantly quicker after $5 \mathrm{~km}$ (Fig. 1).

Metabolic. Although $\mathrm{V}_{2}$ for the $\mathrm{E}$ trials tended to be higher at the 9-km mark, this increase was not significant (Table 1). However, E did produce a significant increase in $\mathrm{VCO}_{2}$ at the $9-\mathrm{km}$ measurement. Ventilation for $\mathrm{C}$ was significantly greater than $\mathrm{P}$ and $\mathrm{C}+\mathrm{E}$ at the 15 -min mark but after $9 \mathrm{~km} \mathrm{C}+\mathrm{E}$ was significantly greater than $\mathrm{P}$ and E.

TABLE 1. Metabolic variables (mean \pm SD) during exercise after ingesting placebo $(P)$, caffeine $(C)$, ephedrine $(E)$, or $C+E$

\begin{tabular}{|c|c|c|c|}
\hline & $15 \mathrm{Min}$ & 30 Min & $9 \mathrm{~km}$ \\
\hline $\begin{array}{l}\dot{\mathrm{VO}_{2}}\left(\mathrm{~L} \cdot \mathrm{min}^{-1}\right) \\
\mathrm{P} \\
\mathrm{C} \\
\mathrm{E} \\
\mathrm{C}+\mathrm{E}\end{array}$ & $\begin{array}{l}3.74 \pm 0.43 \\
3.83 \pm 0.50 \\
3.80 \pm 0.57 \\
3.66 \pm 0.53\end{array}$ & $\begin{array}{l}3.80 \pm 0.53 \\
3.84 \pm 0.52 \\
3.77 \pm 0.47 \\
3.86 \pm 0.58\end{array}$ & $\begin{array}{l}3.85 \pm 0.55 \\
3.85 \pm 0.62 \\
3.85 \pm 0.54 \\
3.97 \pm 0.59\end{array}$ \\
\hline $\begin{array}{l}\dot{\mathrm{V}} \mathrm{CO}_{2}\left(\mathrm{~L} \cdot \mathrm{min}^{-1}\right) \\
\mathrm{P} \\
\mathrm{C} \\
\mathrm{E} \\
\mathrm{C}+\mathrm{E}\end{array}$ & $\begin{array}{l}3.64 \pm 0.49 \\
3.84 \pm 0.56 \\
3.70 \pm 0.67 \\
3.70 \pm 0.58\end{array}$ & $\begin{array}{l}3.69 \pm 0.62 \\
3.81 \pm 0.50 \\
3.63 \pm 0.50 \\
3.79 \pm 0.58\end{array}$ & $\begin{array}{l}3.73 \pm 0.57 \\
3.76 \pm 0.56 \\
3.79 \pm 0.57^{a} \\
3.95 \pm 0.60^{a}\end{array}$ \\
\hline $\begin{array}{l}\dot{V}_{E}\left(L \cdot \min ^{-1}\right) \\
P \\
C \\
E \\
C+E\end{array}$ & $\begin{array}{l}88.4 \pm 10.7 \\
94.5 \pm 12.2^{*} \\
90.6 \pm 14.7 \\
87.5 \pm 10.9 \ddagger\end{array}$ & $\begin{array}{l}93.5 \pm 13.1 \\
99.1 \pm 12.1 \\
94.4 \pm 12.2 \\
96.3 \pm 12.8\end{array}$ & $\begin{array}{r}98.2 \pm 11.8 \\
99.9 \pm 11.7 \\
98.2 \pm 10.9 \\
104.5 \pm 13.1 \dagger^{\star}\end{array}$ \\
\hline
\end{tabular}

${ }^{a} E$ trials significantly different from non-E trials.

* Significantly different from $P$.

‡ Significantly different from C.

† Significantly different from $\mathrm{E}$.

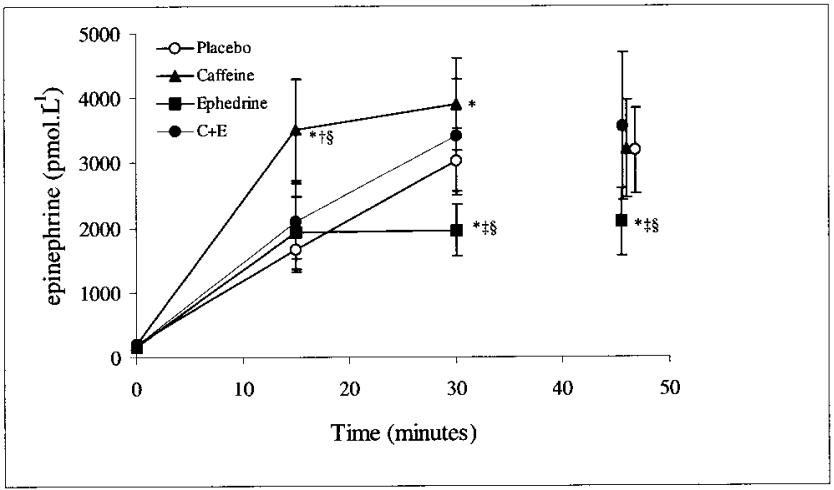

FIGURE 2-Plasma epinephrine before, during, and at the end of the 10-km run. Values are means (SEM). "Significantly different from placebo $(\mathbf{P})$; $\uparrow$ Significantly different from ephedrine $(\mathbf{E})$; $\uparrow$ Significantly different from caffeine $(\mathrm{C})$; §Significantly different from $\mathrm{C}+\mathrm{E}$.

Heart rate and RPE. The $\mathrm{E}$ trials $(\mathrm{E}$ and $\mathrm{C}+\mathrm{E})$ produced a slight but significant increase in the mean heart rate response throughout the run $\left(176 \pm 12\right.$ beats $\left.\cdot \min ^{-1}\right)$ compared with the non-E $(\mathrm{P}$ and $\mathrm{C})$ trials $(174 \pm 13$ beats. $\left.\min ^{-1}\right)$. Although RPE increased over time, the drugs did not affect the sensation of effort despite the fact that pace was different among the trials.

Catecholamines. Exercise produced the typical increase in epinephrine, and this was further affected by the treatments (Fig. 2). C enhanced output, whereas E attenuated the response. Exercise also produced a significant increase in norepinephrine, and this was further increased following $\mathrm{C}$ ingestion $(\mathrm{C}$ and $\mathrm{C}+\mathrm{E}$ ) (Fig. 3). Dopamine also increased as a result of exercise, and after $15 \mathrm{~min}$ dopamine was increased further with $\mathrm{E}$ ingestion ( $\mathrm{E}$ and $\mathrm{C}$ + E) (Fig. 4).

Blood metabolites. After $15 \mathrm{~min}$ of exercise, lactate from the $\mathrm{C}$ trials was significantly higher than the other treatments. By 30 min, $\mathrm{C}$ and $\mathrm{C}+\mathrm{E}$ lactates were higher than $\mathrm{P}$, but by the end of the run only $\mathrm{C}+\mathrm{E}$ trials remained elevated above P. C $+\mathrm{E}$ lactates were also higher than $\mathrm{E}$ at the end of the run. Exercise increased glucose levels, and this response was further increased by C. E trials increased preglucose levels compared with non-E trials (Table 2). E

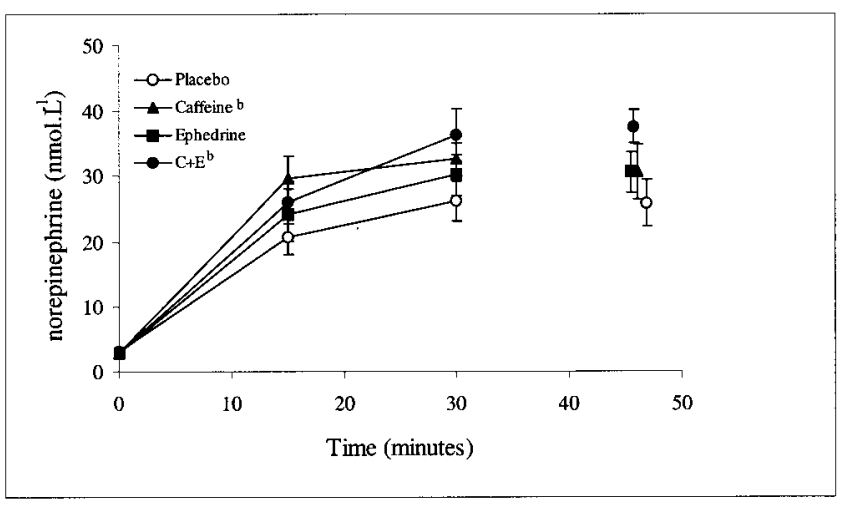

FIGURE 3-Plasma norepinephrine before, during, and at the end of the $10-\mathrm{km}$ run. Values are means (SEM). ${ }^{\mathrm{b}}$ Caffeine $(\mathrm{C})$ trials $(\mathrm{C}$ and $\mathrm{C}$ + epinephrine $[E])$ significantly different from non-C trials $(E$ and placebo $[\mathrm{P}])$. 


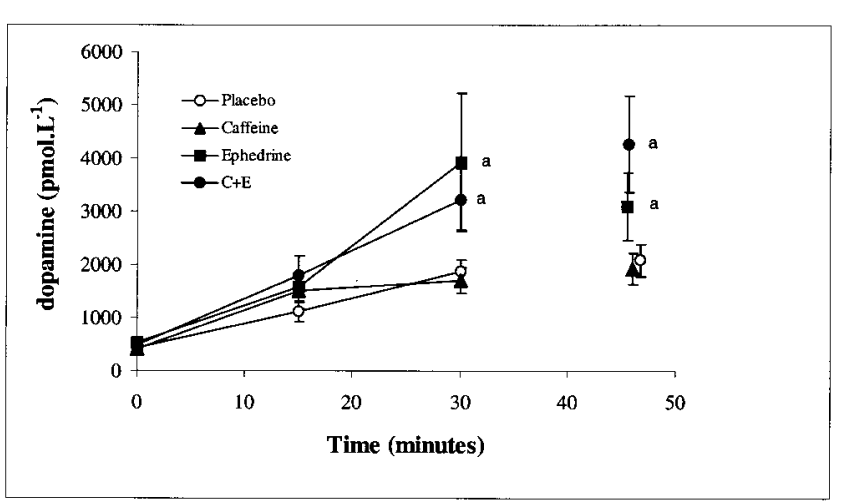

FIGURE 4-Plasma dopamine before, during, and at the end of the $10-\mathrm{km}$ run. Values are means (SEM). ${ }^{a}$ Ephedrine $(\mathrm{E})$ trials $(\mathrm{E}$ and caffeine $[C]+E)$ significantly different from non-E trials $(C$ and placebo $[\mathrm{P}])$.

initially lowered the FFA increase that occurred with exercise, but by the end of exercise FFA was higher in the $\mathrm{E}$ trials (Table 2). Glycerol levels were increased during exercise, and $\mathrm{C}$ further elevated glycerol both before and throughout the $10-\mathrm{km}$ run.

\section{DISCUSSION}

In this study, the main finding was that the $\mathrm{E}$ trials $(\mathrm{E}$ and $\mathrm{C}+\mathrm{E})$ produced significantly faster run times than the non-E trials $(\mathrm{C}$ and $\mathrm{P})$. This reduction of $48 \mathrm{~s}$ represents a small $1.75 \%$ improvement. However, the pace data show that these improvements occurred over the last $5 \mathrm{~km}$. This would suggest a somewhat greater $3.5 \%$ improvement over this $5-\mathrm{km}$ distance, which is similar to the improvements reported for our 3.2-km field trial (3).

It was anticipated from previous work $(5,6)$ that $\mathrm{C}+\mathrm{E}$ might have an additive effect on performance, but this was not the case. One of the possible reasons for this may be the intensity that was sustained during the run. Tarnopolsky (31) concluded that $\mathrm{C}$ may not be ergogenic when the activity requires greater than $90 \% \dot{\mathrm{VO}}_{2 \text { peak }}$ or if the activity is of such intensity that it lasts less than $40 \mathrm{~min}$. When the $\dot{\mathrm{V}}_{2}$ during the run was expressed as a percentage of the $\dot{\mathrm{V}} \mathrm{O}_{2 \text { peak }}$, values ranged from a low of $88 \% \dot{\mathrm{V}} \mathrm{O}_{2 \text { peak }}$ for the $\mathrm{C}+\mathrm{E}$ trials after $15 \mathrm{~min}$ to a high of $96 \% \dot{\mathrm{VO}}_{2 \text { peak }}$ for $\mathrm{C}+$ $\mathrm{E}$ trials at the 9-km distance. With the exception of the $\mathrm{C}+$ E trial after $15 \mathrm{~min}$, all other percentages were above $90 \%$ $\dot{\mathrm{V}} \mathrm{O}_{2 \text { peak }}$. This may be one reason why a significant additive effect of $\mathrm{C}+\mathrm{E}$ or a significant effect of $\mathrm{C}$ alone was not noticed. However, others have shown an ergogenic effect of $\mathrm{C}$ during an incremental exercise test to exhaustion (15) or during high-intensity cycling $(1,4)$ or swimming $(10)$ that involved exercise above $\dot{\mathrm{VO}}_{2 \text { peak }}$.

It is also possible that the type of performance test can influence the ergogenic response observed. Our previous findings documenting an additive effect with $\mathrm{C}$ and $\mathrm{E}$ ingestion involved time to exhaustion as the dependant measure $(5,6)$, which is a more variable test metric than time to complete a prescribed distance $(19,26)$. The additive effects of $\mathrm{C}$ and $\mathrm{E}$ ingestion on time to exhaustion (6) imply that performance is affected by distinct and separate mechanisms following the ingestion of each drug. With $\mathrm{E}$ ingestion, ergogenic effects are evident regardless of the performance test, whereas this is not the case following $\mathrm{C}$ ingestion. During tests that involve exercise to exhaustion, motivation can exert a large impact on the reproducibility of performance (26).

What factors might be involved to account for the ergogenic effect of $E$ on 10-km run times? A peripheral glycogen-sparing mechanism has been proposed $(11,22)$ and shown by others $(13,14,30)$ to account for better performances with $\mathrm{C}$.

TABLE 2. Blood metabolites (mean $\pm S D$ ) before, during, and at the end of exercise after ingesting placebo $(P)$, caffeine $(C)$, ephedrine $(E)$, or $C+E$

\begin{tabular}{|c|c|c|c|c|}
\hline & Before & $15 \mathrm{Min}$ & 30 Min & End \\
\hline $\begin{array}{l}\text { Lactate }\left(\mathrm{mmol}^{\circ} \cdot \mathrm{L}^{-1}\right) \\
\mathrm{P} \\
\mathrm{C} \\
\mathrm{E} \\
\mathrm{C}+\mathrm{E}\end{array}$ & $\begin{array}{l}1.17 \pm 0.42 \\
1.49 \pm 0.57 \\
1.46 \pm 0.63 \\
1.61 \pm 0.53\end{array}$ & $\begin{array}{l}4.92 \pm 1.91 \\
7.16 \pm 3.45^{\star}+\S \\
5.81 \pm 2.93 \\
5.77 \pm 2.93\end{array}$ & $\begin{array}{l}5.79 \pm 2.10 \\
7.27 \pm 2.54^{*} \\
6.41 \pm 3.41 \\
7.38 \pm 3.11^{*}\end{array}$ & $\begin{array}{l}7.26 \pm 2.25 \\
7.96 \pm 2.25 \\
6.89 \pm 2.46 \\
8.87 \pm 2.72^{*} \dagger\end{array}$ \\
\hline 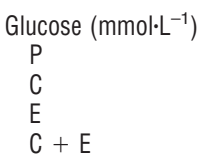 & $\begin{array}{l}3.526 \pm 0.512 \\
3.582 \pm 0.838 \\
4.408 \pm 1.306^{a} \\
3.692 \pm 0.771^{a}\end{array}$ & $\begin{array}{l}4.022 \pm 0.959 \\
4.298 \pm 1.361^{b} \\
3.582 \pm 0.755 \\
4.077 \pm 0.815^{b}\end{array}$ & $\begin{array}{l}4.959 \pm 1.466 \\
5.400 \pm 1.223^{b} \\
4.518 \pm 0.992^{a} \\
5.014 \pm 1.344^{a b}\end{array}$ & $\begin{array}{l}6.116 \pm 1.366 \\
6.667 \pm 1.521^{b} \\
5.235 \pm 1.317 \\
6.502 \pm 1.400^{b}\end{array}$ \\
\hline $\begin{array}{l}\text { FFA }\left(\mathrm{mmol}^{-1} \mathrm{~L}^{-1}\right) \\
\qquad \begin{array}{l}\mathrm{P} \\
\mathrm{C} \\
\mathrm{E} \\
\mathrm{C}+\mathrm{E}\end{array}\end{array}$ & $\begin{array}{l}0.204 \pm 0.105 \\
0.193 \pm 0.113 \\
0.190 \pm 0.100 \\
0.195 \pm 0.057\end{array}$ & $\begin{array}{l}0.231 \pm 0.077 \\
0.204 \pm 0.079 \\
0.165 \pm 0.055^{a} \\
0.199 \pm 0.043^{a}\end{array}$ & $\begin{array}{l}0.265 \pm 0.078 \\
0.224 \pm 0.076 \\
0.224 \pm 0.088 \\
0.259 \pm 0.099\end{array}$ & $\begin{array}{l}0.360 \pm 0.177 \\
0.307 \pm 0.136 \\
0.366 \pm 0.149^{a} \\
0.375 \pm 0.166^{a}\end{array}$ \\
\hline $\begin{array}{l}\text { Glycerol }\left(\mathrm{mmol}^{\circ} \mathrm{L}^{-1}\right) \\
\mathrm{P} \\
\mathrm{C} \\
\mathrm{E} \\
\mathrm{C}+\mathrm{E}\end{array}$ & $\begin{array}{l}0.064 \pm 0.015 \\
0.077 \pm 0.024^{b} \\
0.070 \pm 0.018 \\
0.075 \pm 0.012^{b}\end{array}$ & $\begin{array}{l}0.139 \pm 0.042 \\
0.154 \pm 0.038^{b} \\
0.141 \pm 0.033 \\
0.149 \pm 0.024^{b}\end{array}$ & $\begin{array}{l}0.205 \pm 0.062 \\
0.225 \pm 0.052^{b} \\
0.200 \pm 0.049 \\
0.218 \pm 0.049^{b}\end{array}$ & $\begin{array}{l}0.266 \pm 0.075 \\
0.286 \pm 0.070^{b} \\
0.280 \pm 0.076 \\
0.293 \pm 0.073^{b}\end{array}$ \\
\hline
\end{tabular}

\footnotetext{
${ }^{a} E$ trials significantly different from non-E trials.

${ }^{b} \mathrm{C}$ trials significantly different from non-C trials.

* Significantly different from $P$.

$\dagger$ Significantly different from $\mathrm{E}$.

$\S$ Significantly different from $\mathrm{C}+\mathrm{E}$.
} 
However, our findings are not consistent with an effect of $E$ on glycogen utilization. Blood glucose levels were decreased following $\mathrm{E}$ ingestion that would indicate an increased rather than a decreased reliance on intramuscular glycogen. Furthermore, FFA levels, although elevated after exercise for the E trials, were not different from the non-E trials during the first $30 \mathrm{~min}$ of exercise. Finally, respiratory exchange ratios were similar among all trials (data not shown) and close to 1.0 throughout the performance of the $10-\mathrm{km}$ run, indicative of a high rate of carbohydrate utilization regardless of the treatment. Clearly, it is difficult to substantiate or refute a proposed mechanism of action from blood concentrations, which represent a dynamic balance between turnover and clearance. Whole body tracer studies together with skeletal muscle analyses are necessary to delineate the effects of $\mathrm{E}$ on carbohydrate metabolism.

It is known that $\mathrm{E}$ is a sympathomimetic agent with both peripheral and central nervous system (CNS) effects (20). E will increase the release of monoamines (specifically, dopamine) in the periphery and the CNS (20) under resting conditions. Furthermore, it is known that exercise also will cause an increased release of catecholamines in the periphery and CNS $(25,27)$. However, exercise does not appear to mask the effect of $\mathrm{E}$ ingestion on dopamine turnover as indicated by the increased blood concentrations of dopamine in this and our previous study (5). Since dopamine does not cross the blood-brain barrier (20), our elevated circulating dopamine levels during the E trials might appear more consistent with a peripheral effect of E. However, the barrier's effectiveness is much less pronounced in the hypothalamus (7), an area where dopamine influence is a factor modulating mood state (2). Thus, the increase in circulating dopamine could reflect a greater effect of the drug on CNS function. The effects of $\mathrm{E}$ on $10-\mathrm{km}$ run times, therefore, could be mediated via a central mechanism that remained independent of peripheral effects on substrate utilization.

\section{REFERENCES}

1. Anselme, F., K. Collomp, B. Mercier, S. Ahmaidi, and C. PreFAUT. Caffeine increases maximal anaerobic power and blood lactate concentration. Eur. J. Appl. Physiol. Occup. Physiol. 65: $188-191,1992$.

2. Bear, M. F., B. W. Connors, and M. A. Paradiso. Neuroscience: Exploring the Brain. Baltimore, MD: Williams \& Wilkins, 1996, pp. 402-430.

3. Bell, D. G., and I. Jacobs. Combined caffeine and ephedrine ingestion improves run times of Canadian Forces Warrior Test. Aviat. Space. Environ. Med. 70:325-329, 1999.

4. Bell, D. G., I. Jacobs, and K. Ellerington. The effect of caffeine and ephedrine ingestion on anaerobic exercise performance. Med. Sci. Sports Exerc. 33:1399-1403, 2001.

5. Bell, D. G., I. Jacobs, and J. Zamecnik. Effects of caffeine, ephedrine and their combination on time to exhaustion during high-intensity exercise. Eur. J. Appl. Physiol. Occup. Physiol. 77:427-433, 1998.

6. Bell, D. G., I. Jacobs, and J. Zamecnik. Reply to Morton Letter. Eur. J. Appl. Physiol. 80:611-612, 1999.

7. BLoom, F. E. Neurohumoral transmission and the central nervous system. In: Goodman and Gillman's The Pharmacological Basis of Therapeutics, A. G. Gillman, T. W. Rall, A. S. Nies, and P. Taylor (Eds.). New York: Pergamon Press, 1990, pp. 244-268.
The reader must remain cognizant of the inherent biological variability associated with the performance of the $10-\mathrm{km}$ run or other similar tests that involve the time to complete a predetermined amount of work. The intraclass correlation coefficients that were calculated for the familiarization and $\mathrm{P}$ trials or for the four experimental sessions suggest that the between-subject variance accounted for between 62 and $74 \%$ of the total variance of the run times. The remaining variance would be attributed to the withinsubject error and treatment effects. The question remains as to the physiological significance of the small improvement noted for the E trials amid this inherent biological variability associated with the reproducibility of the $10-\mathrm{km}$ performance. It must be remembered, however, that the effect of E was consistent among our subjects and demonstrable during both $\mathrm{E}$ trials $(\mathrm{E}$ and $\mathrm{C}+\mathrm{E})$ for 8 of our 12 subjects. In addition, the small $95 \%$ confidence interval of $0.3 \mathrm{~min}$ for the within-subject variance during the experimental treatments attests to the consistency of the E effect among the subjects. Thus, we believe that the statistical effect found for $\mathrm{E}$ is real and is of physiological significance for the performance of the $10-\mathrm{km}$ run.

In conclusion, $\mathrm{E}$ ingestion significantly decreased $10-\mathrm{km}$ run times by approximately $48 \mathrm{~s}$, and this improvement occurred over the last half of the run. Furthermore, an ergogenic effect of $\mathrm{C}$ was not evident either when the drug was administered alone or in combination with $\mathrm{E}$.

The authors are grateful to Sandoz Canada for providing caffeine and Roberts Pharmaceutical Canada for providing ephedrine. The authors also acknowledge the technical assistance of Mrs. Ingrid Smith, Mrs. Debbie Kerrigan-Brown, Mr. Jan Pope, Mr. Gary Seabrook, and Ms. Nancy Grinberg.

Address for correspondence: Douglas G. Bell, B.Sc., M.Sc., Defence and Civil Institute of Environmental Medicine, P.O. Box 2000, Toronto, Ontario, Canada M3M 3B9; E-mail: doug.bell@ dciem.dnd.ca.

8. Boobis, L. H., and R. J. Maughan. A simple one-step enzymatic fluorometric method for the determination of glycerol in $20 \mu \mathrm{L}$ of plasma. Clin. Chim. Acta 132:173-179, 1983.

9. Borg, G. A. V. Psychological bases of perceived exertion. Med. Sci. Sports. Exerc. 14:377-381, 1982.

10. Collomp, K., S. Ahmaidi, J. C. Chatard, M. Audran, and C. PREFAUT. Benefits of caffeine ingestion on sprint performance in trained and untrained swimmers. Eur. J. Appl. Physiol. Occup. Physiol. 64:377-380, 1992.

11. Costill, D. L., G. P. Dalsky, and W. J. Fink. Effects of caffeine ingestion on metabolism and exercise performance. Med. Sci. Sports. 10:155-158, 1978.

12. Dodd, S. L., R. A. Herb, and S. K. Powers. Caffeine and exercise performance: an update. Sports Med. 15:14-23, 1993.

13. Erickson, M. A., R. J. Schwarzkopf, and R. D. McKenzie. Effects of caffeine, fructose, and glucose ingestion on muscle glycogen utilization during exercise. Med. Sci. Sports Exerc. 19:579-583, 1987.

14. Essig, D. A., D. L. Costill, and P. J. Van Handel. Effects of caffeine ingestion on muscle glycogen and lipid during leg ergometer cycling. Int. J. Sports Med. 1:188-193, 1980.

15. Flinn, S., J. Gregory, L. R. McNaughton, S. Tristram, and P. DAVIES. Caffeine ingestion prior to incremental cycling to exhaustion in recreational cyclists. Int. J. Sports Med. 11:188-193, 1990. 
16. GAGnon, J., J. M. Roth, W. F. Finzer, et al. Superanova: Accessible General Linear Modeling. CA: Abacus Concepts, Inc., 1989, pp. 175-214.

17. Gillies, H., W. E. Derman, T. D. Noakes, P. Smith, A. Evans, and G. GABRIELS. Pseudoephedrine is without ergogenic effects during prolonged exercise. J. Appl. Physiol. 81:2611-2617, 1996.

18. Graham, T. E., and L. L. Spriet. Performance and metabolic responses to a high caffeine dose during prolonged exercise. J. Appl. Physiol. 71:2292-2298, 1991.

19. Hickey, M. S., D. L. Costill, G. K. McConell, J. J. Widrick, and $\mathrm{H}$. TANAKA. Day to day variation in time trial cycling performance. Int. J. Sports Med. 13:467-470, 1992.

20. Hoffman, B. B., and R. J. LefKowitz. Catecholamines and sympathomimetic drugs. In: Goodman and Gillman's The Pharmacological Basis of Therapeutics, A. G. Gillman, T. W. Rall, A. S. Nies, and P. Taylor (Eds.). New York: Pergamon Press, 1990, pp. 187-220.

21. Howell, D. C. Statistical Methods for Psychology. Belmont, CA: Duxbury Press, 1997, pp. 490-493.

22. Ivy, J. L., D. L. CostiLl, W. J. FinK, and R. W. Lower. Influence of caffeine and carbohydrate feedings on endurance performance. Med. Sci. Sports. 11:6-11, 1979.

23. Luftus, G. R., and M. E. J. Masson. Using confidence intervals in within-subjects design. Psychonomic Bull. Rev. 1:467-490, 1994.

24. Maughan, R. J. A simple, rapid method for the determination of glucose, lactate, pyruvate, alanine, 3-hydroxybutyrate and aceto- acetate on a single 20- $\mu$ l blood sample. Clin. Chim. Acta 122: 231-240, 1982.

25. Mazzeo, R. S. Catecholamine responses to acute and chronic exercise. Med. Sci. Sports Exerc. 23:839-845, 1991.

26. McLellan, T. M., S. S. Cheung, and I. Jacobs. Variability of time to exhaustion during submaximal exercise. Can. J. Appl. Physiol. 20:39-51, 1995.

27. Meeusen, R., and K. De Meirleir. Exercise and brain neurotransmission. Sports Med. 20:160-188, 1995.

28. Nehlig, A., and G. Debry. Caffeine and sports activity: a review. Int. J. Sports Med. 15:215-223, 1994.

29. SASKi, H., J. MAEDA, S. Usui, and T. IshiKo. Effects of sucrose and caffeine ingestion on performance of prolonged strenuous running. Int. Sports Med. 8:203-207, 1987.

30. Spriet, L. L., D. A. Maclean, D. J. Dyck, E. Hultman, G. Cederblad, and T. E. Graham. Caffeine ingestion and muscle metabolism during prolonged exercise in humans. Am. J. Physiol. 262:E891-E898, 1992.

31. Tarnopolsky, M. A. Caffeine and endurance performance. Sports Med. 18:109-125, 1994.

32. ZAMECNIK, J. Quantification of epinephrine, norepinephrine, dopamine, metanepherine, and normetanephedrine in human plasma using negative ion chemical ionization GC-MS. Can. J. Anal. Sci. Spectroscopy. 42:106-112, 1997. 